\title{
Technical condition of welded load-bearing metal structures of operated agricultural hoisting cranes
}

\author{
Alexander Scherbakov ${ }^{1}$, Anna Babanina ${ }^{2, *}$, Ivan Kochetkov ${ }^{3}$ and Pavel Khoroshilov ${ }^{3}$ \\ ${ }^{1}$ Saint Petersburg State University of Architecture and Civil Engineering, 4, 2 Krasnoarmeiskaya str., \\ 190005, Saint Petersburg, Russia \\ ${ }^{2}$ Peter the Great St. Petersburg Polytechnic University, 29, Polytechnicheskaya str., 195251, Saint \\ Petersburg, Russia \\ ${ }^{3}$ Moscow State University of Civil Engineering, 26, Yaroslavskoye shosse, 129337, Moscow, Russia
}

\begin{abstract}
The paper considers the methodology for assessing the technical condition of welded load-bearing metal structures of operated agricultural hoisting cranes. In the course of the study, the relationship between structural, mechanical and magnetic parameters was established during cyclic elastic-plastic deformation of low-carbon and low alloy steels. Based on the analysis, it was concluded that the dependence of the minimum values of the magnetic parameter on the acting stresses $\operatorname{Hp}(\sigma)$ is influenced by the metal structure and its chemical composition. It has been established that the coarser-grained structure of the studied steels under elastic-plastic deformation contributes to a shift in the minimum values of Hp towards lower acting stresses; an increase in the strength characteristics of steels shifts the minimum of Hp toward large values of s, which must be taken into account when conducting technical diagnostics of the elements of the operating metal structures of hoisting cranes. Based on the results of the study, a method for determining the acting stresses in the elements of the metal structures of hoisting cranes was developed, which, by the nature and magnitude of the change in the residual magnetization of the scattering field during their stepwise loading (unloading), allows judging the magnitude of the acting stresses. The work also presents a methodology for assessing the technical condition of welded load-bearing metal structures of hoisting cranes based on the integrated use of passive flux-gate and other control methods, which allows determining the acting stresses used in strength calculations in the identified hazardous zones of concentration of stresses in the elements of metal structures.
\end{abstract}

\section{Introduction}

One of the main problems in ensuring reliable and safe operation of welded loadbearing metal structures of operated hoisting cranes is the assessment of their actual stressstrain state, and indirect methods for determining stresses based on the use of various

\footnotetext{
*Corresponding author: nusha_babanina@mail.ru
} 
physical effects, in particular, the magnetomechanical phenomenon, are of great importance [1- 2], including the magnetoelastic effect and magnetomechanical hysteresis. Their use is important because there are new possibilities for studying the laws of, respectively, reversible and irreversible magnetoelastic phenomena during loading and unloading of metal structures of hoisting cranes, which allows monitoring and evaluating the stress-strain state (SSS) of metal structures in order to further predict reliable and safe operation, including under conditions of exposure to corrosion media and taking into account the various structural state of the metal.

However, the control problem is complicated by the fact that the structural state of the metal, its chemical composition, and the magnetic and mechanical background of structural elements are often unknown. Therefore, there is an urgent need for experimental studies involving a wide range of materials with different initial structural states.

Reliable and safe operation of welded load-bearing metal structures of hoisting cranes can be ensured only with the correct and timely monitoring of the technical condition using a complex of modern instruments, methods and techniques of non-destructive testing at the stages of manufacturing, installation and operation, reliable prediction of durability, qualified implementation of measures to ensure and increase efficiency.

The issues of the influence of external loads of various intensities on the distribution of deformations, stresses and stress concentration in areas of possible destruction of the metal structures of hoisting cranes require further study. In this connection, it is necessary not only to test laboratory samples, but to develop various field and bench methods and ways for testing units, maquettes, models that have both constructive and technological similarity with the most dangerous units of real structures in order to develop constructive and technological solutions, as well as on operating metal structures of hoisting cranes.

The tasks of assessing the stress-strain state in the elements and units of operated welded metal structures of hoisting cranes would be more reliably solved after considering issues such as:

- identification of stress concentration (SC) zones by continuous scanning without preparatory work;

- determination of the nature of the operation of the SC zones (elastic or plastic region of deformation);

- comparison according to the degree of danger of identified SC zones:

- ability to assess the acting stresses in the local hazardous SC zones during both at loading and unloading the structure (depending on the conditions of its operation);

- determination of the correspondence of the acting stresses in the SC zones to values up to or above the limit of proportionality of the metal;

- assessment of the acting stresses on the proximity to the yield strength in the elasticplastic region of deformation;

- degree of development of plastic deformation in the identified SC zones;

- identification of local and general corrosion damage with an assessment of their degree of danger;

- assessment of the degree of danger of various zones of welded joints (weld zone, fusion zone with an adjacent area of overheating);

- possibility of periodic or continuous monitoring in the most dangerous SC zones;

- presence of a relationship between the magnetic parameter $H_{p}$, the initial microstructure, and the stresses acting in the metal when constructing a tensile diagram in the load - strain coordinates provides the basis for experimental studies to expand and refine the dependence $\mathrm{H}_{\mathrm{p}}(\sigma)$ during cyclic elastic-plastic deformation of structural steels.

Therefore, in the studies of the authors V.E. Gordienko, N.V. Ovchinnikov, A.O. Baksheev and A. Shcherbakov tested the applicability of the experimental dependences $\mathrm{H}_{\mathrm{p}}(\sigma)$ obtained on laboratory samples on welded load-bearing metal structures of hoisting 
cranes. In this case, we used the results of studies obtained on samples of low-carbon steel 08ps and low-alloy steel $09 \mathrm{Mn} 2 \mathrm{Si}$ with different initial microstructures: coarse-grained (in the as-received condition, after annealing at temperatures of 900 and $1050{ }^{\circ} \mathrm{C}$ ), fine-grained (obtained during thermal cycling and recrystallization annealing), as well as the structure obtained after cold plastic deformation (fractional rolling to a degree of deformation of $50 \%$ ). To study the magnetomechanical background of the samples, magnetic marks (local magnetization) and mechanical damage (local hardening) were applied to parts of them, and the effect of the thickness of the nonmagnetic protective coating on the degree of change of the magnetic parameter $\mathrm{H}_{\mathrm{p}}$ was evaluated. The cyclic stepwise deformation of the samples was carried out both in the elastic and in the plastic regions. As a result of laboratory studies, a relationship was found between the mechanical, structural and magnetic parameters of the studied steels, which is of great practical importance in assessing the technical condition of welded metal structures [3-4].

The purpose of this article is to develop a method for assessing the technical condition of welded load-bearing metal structures of operated hoisting cranes.

\section{Materials and methods}

The study of the stress-strain state of samples under elastic-plastic deformation was carried out on structural steels with different chemical compositions and initial microstructures. For mechanical testing, samples were made from 08ps and 09Mn2Si steels, which were subjected to preliminary processing to obtain a coarse-grained and fine-grained structure in the following modes:

- factory as-received condition;

- as-received condition + annealing at 900 and $1050{ }^{\circ} \mathrm{C}$;

- as-received condition + thermal cycling;

- as-received condition + rolling for the degree of deformation $\varepsilon=50 \%$;

- rolling at $\varepsilon=50 \%+$ recrystallization annealing.

Mechanical tests of samples from 08ps and 09Mn2Si structural steels during their elastic deformation were carried out with stepwise loading and unloading at a speed of 2 $\mathrm{mm} / \mathrm{min}$. During stops, the values of the magnetic field scattering $\mathrm{H}_{\mathrm{p}}$ were measured in the center of each sample (in the artificially created SC zone), while constant contact of the flux-gate transducer fixed perpendicular to the surface of the control zone was carried out during the entire test.

The calculation of the confidence interval for the obtained dependences was carried out according to GOST 8.207-76 "Direct measurements with multiple observations. Methods of processing the results of observations." According to the calculation results, the confidence interval does not exceed $1.95 \mathrm{~A} / \mathrm{m}$ (with a confidence probability of $P=0.98$ and Student's coefficient $t_{p}=3.10$ ).

It should be noted that, depending on the initial state, magnetic and mechanical background of the samples, the initial values of $\mathrm{H}_{\mathrm{p}}$ (before applying an external load) on the sample surface in different zones can vary significantly. However, the character of the dependence of $\mathrm{H}_{\mathrm{p}} \mathrm{p}$ on the acting stresses $\mathrm{s}$ does not change qualitatively. Therefore, it was of interest to study the dependence $\mathrm{H}_{\mathrm{p}}(\sigma)$ in the zone of maximum stresses, which was modeled by a decrease in the cross-sectional area in the central part of the sample by creating lateral radius grooves.

\section{Results and discussion}

During mechanical tests, it was shown that, regardless of the chemical composition and 
initial microstructure, when the samples are stretched in the elastic region of deformation with increasing acting stresses, the intensity of the scattering magnetic field decreases. With decreasing stresses $s$ (unloading), the $\mathrm{H}_{\mathrm{p}}$ values increase (Figs. 1-3).

a)

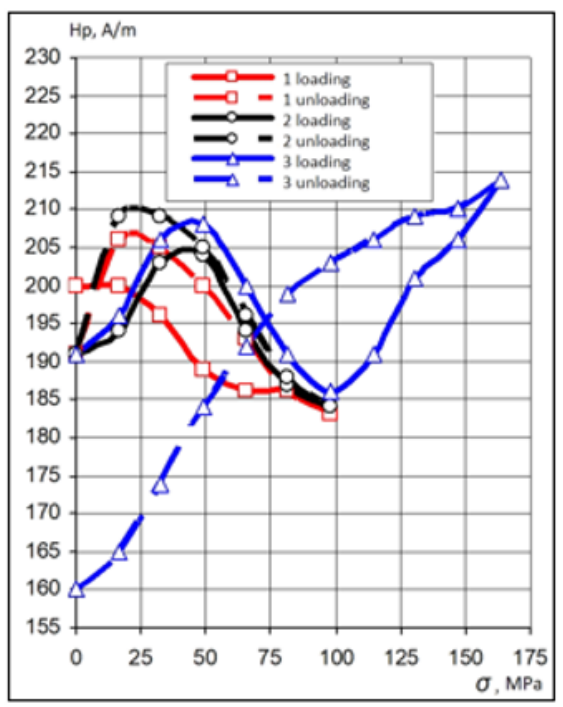

b)

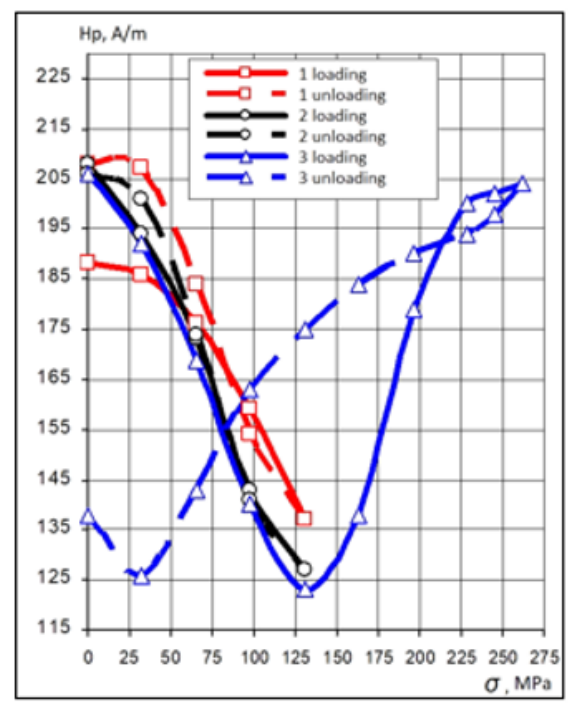

Fig. 1. Dependence of the scattering magnetic field strength $H_{p}$ on the acting stresses s under uniaxial tension of specimens from steel 09Mn2Si $(a)$ and 08ps $(b)$ in the as-received condition.

It is characteristic of all steels that the greatest changes in the magnetic field strength of scattering $\mathrm{H}_{\mathrm{p}}$ occur during the 1st cycle of elastic loading-unloading, and, regardless of the initial microstructure, an increase in the acting stresses $s$ leads to a decrease in the magnetic field strength. In the process of cyclic voltage changes due to the application and removal of external loads, a magnetic hysteresis loop is formed. After the 1st loading-unloading cycle, it is most often not closed: the final values of the magnetic field strength $\mathrm{H}_{\mathrm{p}}$ after unloading do not coincide with the initial values. After the 2 nd and subsequent cycles of elastic deformation, the magnetic hysteresis loop closes. During the second cycle, the $\mathrm{H}_{\mathrm{p}}$ values during loading and unloading of the samples approach each other, which is noticeable by the location of the branches of the magnetic hysteresis loop, while the final $\mathrm{H}_{\mathrm{p}}$ values practically coincide with the initial ones.

It should be noted that the $\mathrm{H}_{\mathrm{p}}(\sigma)$ curves at the 3rd and subsequent loading cycles mainly repeat the loading curves of the 2 nd cycle. Therefore, regardless of the initial microstructure, after the 1st loading-unloading cycle, the initial magnetic background of the samples is erased, as a result of which an increase in the number of cycles practically does not change the nature of the course of the $\mathrm{H}_{\mathrm{p}}(\sigma)$ curves. 
a)

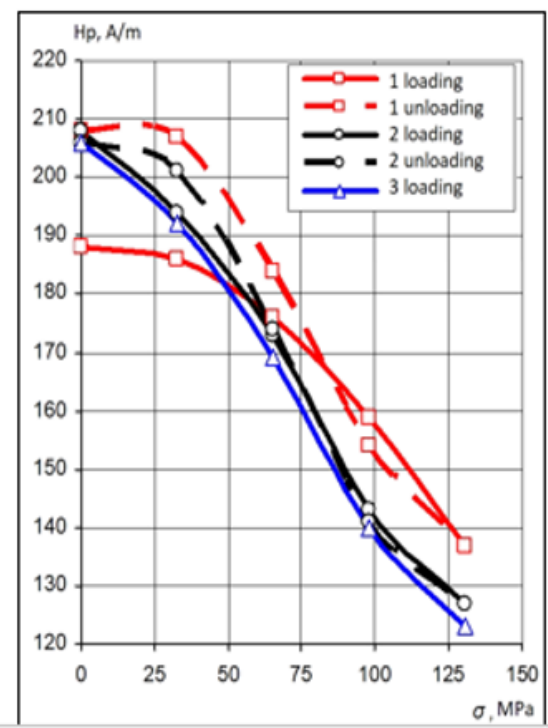

b)

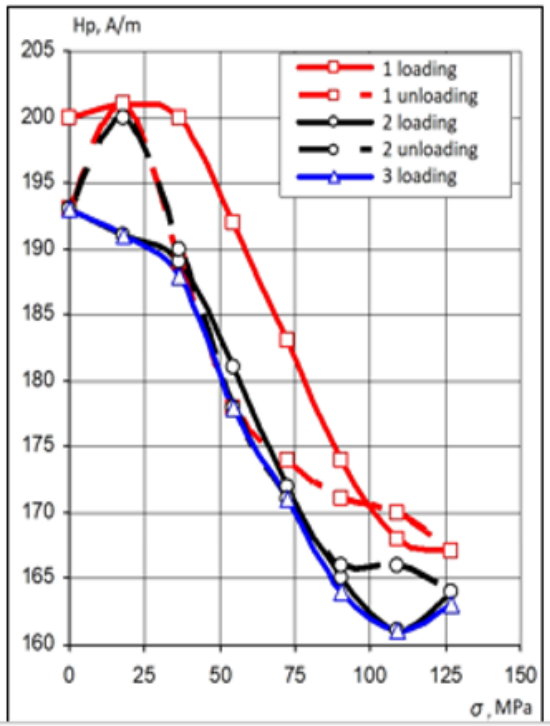

Fig. 2. Dependence of the magnetic field strength $H_{p}$ on uniaxial tensile stresses $\sigma$ of steel samples after annealing: $a-09 \mathrm{Mn} 2 \mathrm{Si}$ at $1050{ }^{\circ} \mathrm{C}, b-08 \mathrm{ps}$ at $900{ }^{\circ} \mathrm{C}$.

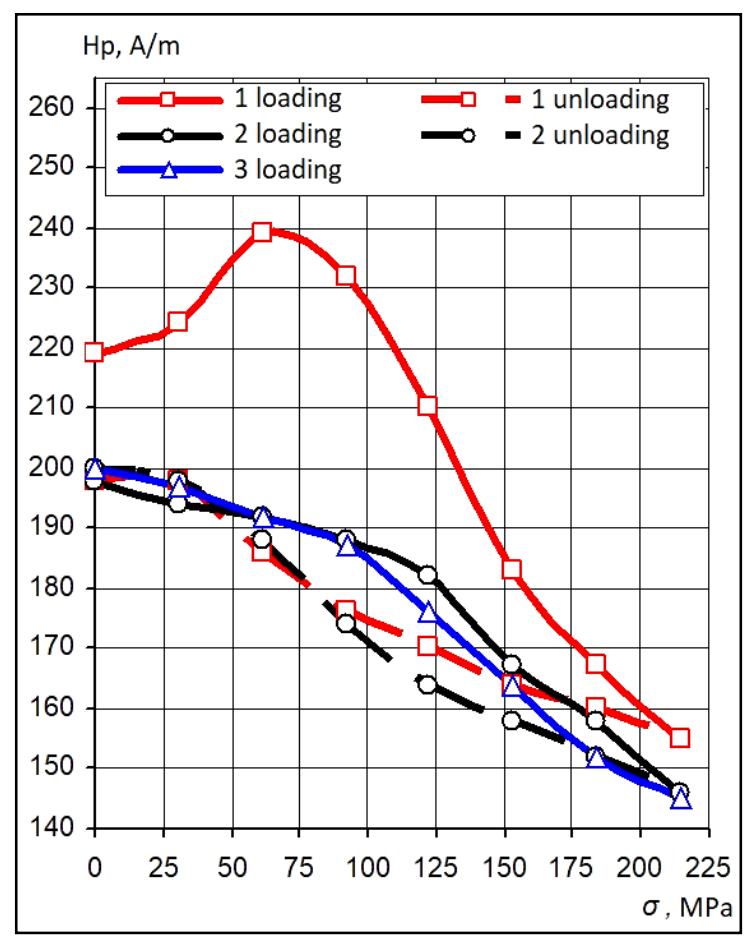

Fig. 3. Dependence of the magnetic field strength $\mathrm{H}_{\mathrm{p}}$ on uniaxial tensile stresses s of 08ps steel samples after rolling at $\varepsilon=50 \%$.

Preliminary cold plastic deformation has a significant effect on the change in $\mathrm{H}_{\mathrm{p}}(\sigma)$ under tension. In Fig. 3, there is a noticeable significant difference in the behavior of the 
$\mathrm{H}_{\mathrm{p}}(\sigma)$ dependence upon the 1st loading and unloading of a deformed sample in comparison with coarse-grained and fine-grained samples. In a subsequent cycle, the magnetic hysteresis loop becomes much narrower. In this case, a decrease in $\mathrm{H}_{\mathrm{p}}$ values is also observed during loading of the sample and their increase is observed during unloading. It should be noted that during the elastic deformation of samples subjected to preliminary cold rolling, a clearly pronounced magnetic effect is observed at the initial stage (Fig. 3). At the 1st loading, with an increase in stresses, the $\mathrm{H}_{\mathrm{p}}$ values initially increase, then decrease. After complete unloading of the samples, this effect is removed. The dependence $\mathrm{H}_{\mathrm{p}}(\sigma)$ is less pronounced upon deformation of samples subjected to preliminary heat treatment, in which compression stresses are formed in the surface layer during cooling.

A similar change in the mechanical properties during deformation is called the Bausinger effect, which consists in reducing the metal resistance to small plastic deformations after preliminary plastic deformation of the opposite sign. Pure iron and steel have a significant tendency to manifest the Bausinger effect. The manifestation of this effect under alternating loading is expressed in a distortion of the shape of the plastic hysteresis loop, at least in the first few cycles: the transition to the plastic region in each subsequent half-cycle can occur at a lower stress than in the previous one.

When the samples are stretched in the plastic region, a different picture is observed: with an increase in the acting stresses, the scattering magnetic field strength $\mathrm{H}_{\mathrm{p}}$ increases. In Fig. 4 shows typical dependences of $\mathrm{H}_{\mathrm{p}}$ on the acting stresses during tension of samples from 08ps and 09Mn2Si steels with a coarse-grained structure obtained as a result of hightemperature annealing (as-received condition + annealing at $1050{ }^{\circ} \mathrm{C}$ ). It can be seen that in the steels under study, after the $\mathrm{H}_{\mathrm{p}}$ values drop to the minimum, they begin to rise in the region of plastic deformation. When the samples are unloaded, magnetic hysteresis occurs, and the final values of $\mathrm{H}_{\mathrm{p}}$ do not coincide with the initial values.

a)

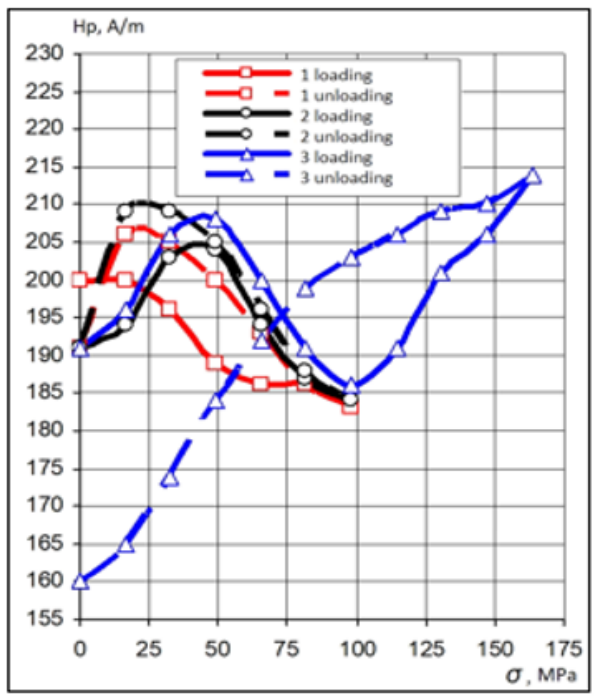

b)

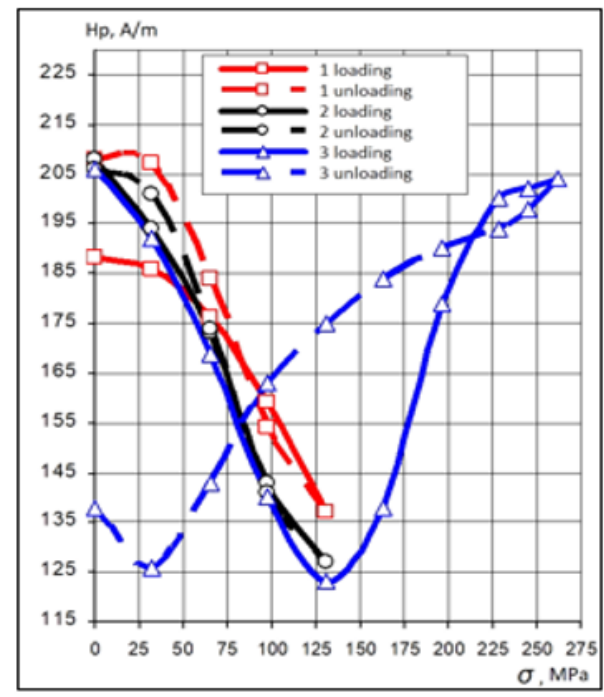

Fig. 4. Dependence of the magnetic field strength $\mathrm{H}_{\mathrm{p}}$ on uniaxial tensile stresses for steel samples in a state (as-received condition + annealing at $1050{ }^{\circ} \mathrm{C}$ ): $a-08 \mathrm{ps}, b-09 \mathrm{Mn} 2 \mathrm{Si}$.

Sample testing with a finer-grained structure (as-received condition + annealing at 900 $\left.{ }^{\circ} \mathrm{C}\right)$ somewhat changes the dependence $\mathrm{H}_{\mathrm{p}}(\sigma)$, both in the elastic and in the plastic region. So, for example, for all steels during loading, the minimum values of the scattering magnetic field strength $\mathrm{H}_{\mathrm{p}}$ shift toward higher stresses (Fig. 5). However, when the load is 
removed in the initial stage, there is a greater delay in the $\mathrm{H}_{\mathrm{p}}$ values than for coarsergrained samples obtained after annealing at $1050^{\circ} \mathrm{C}$. In this case, the final values of $\mathrm{H}_{\mathrm{p}}$ also do not coincide with the initial values. The tension of samples with a finer-grained structure (as-received condition) is marked by an even larger shift of the minimum $\mathrm{H}_{\mathrm{p}}$ values towards higher acting stresses $s$ and a more pronounced magnetic $\mathrm{H}_{\mathrm{p}}$ hysteresis during unloading of the samples in the plastic region (Fig. 6), which is most clearly manifested on low-alloy steel 09Mn2Si.

a)

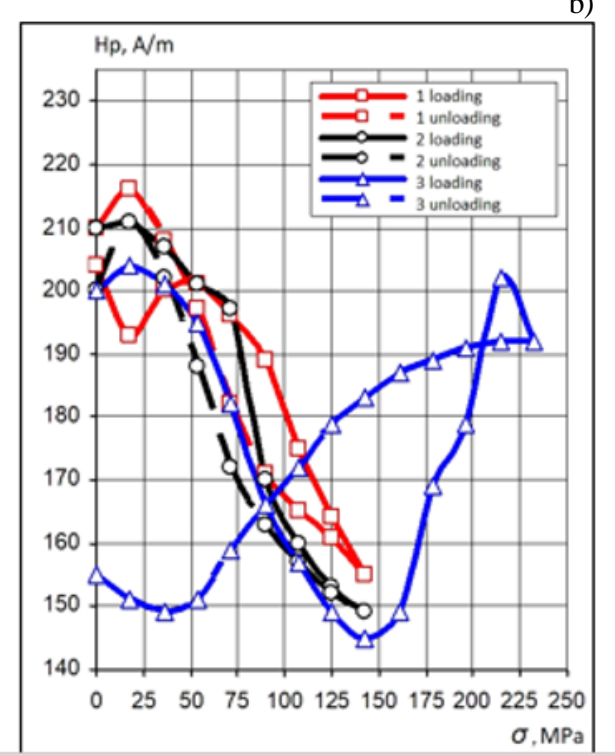

b)

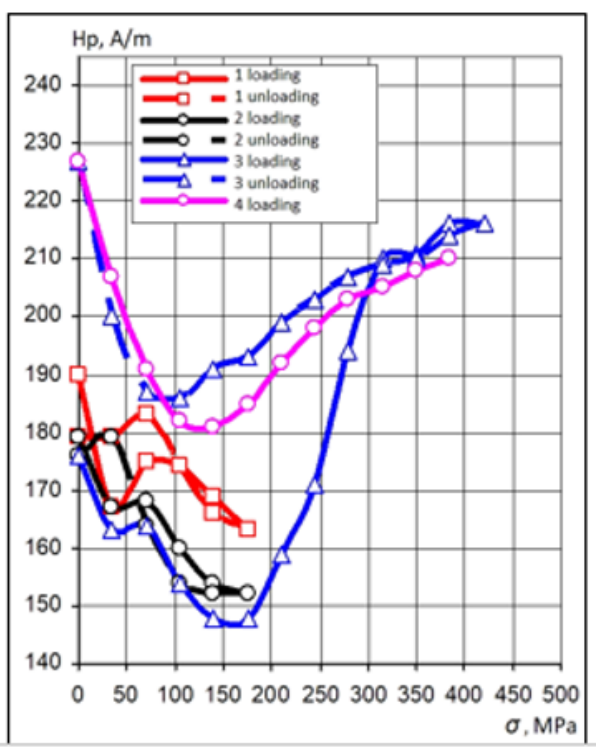

Fig. 5. Dependence of the magnetic field strength $H_{p}$ on uniaxial tensile stresses for steel samples in a state (as-received condition + annealing at $900^{\circ} \mathrm{C}$ ): $a-08 \mathrm{ps}, b-09 \mathrm{Mn} 2 \mathrm{Si}$.

a)

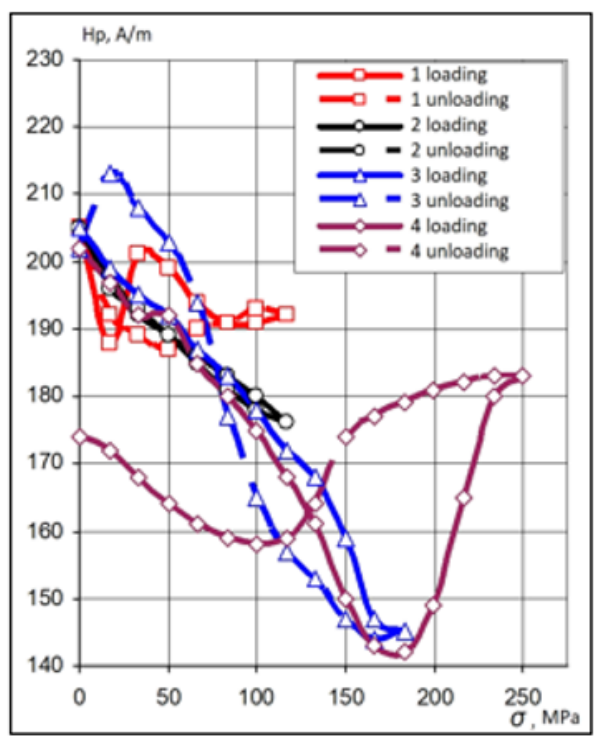

b)

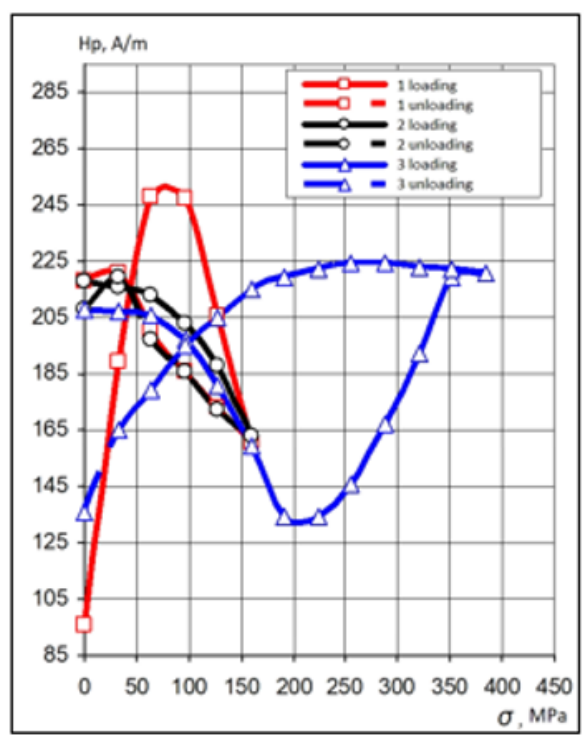

Fig. 6. Dependence of the magnetic field strength Hp on uniaxial tensile stresses for steel samples in the as-received condition: $a-08 \mathrm{ps}, b-09 \mathrm{Mn} 2 \mathrm{Si}$. 
In Fig. 7 shows a typical dependence of the magnetic field strength $\mathrm{H}_{\mathrm{p}}$ on the acting stresses s for steel 08ps in the state (rolling by $\varepsilon=50 \%$ + recrystallization annealing), which is also typical for steel $09 \mathrm{Mn} 2 \mathrm{Si}$. The presence of a fine-grained structure obtained during recrystallization annealing leads to a shift in the minimum values of $\mathrm{H}_{\mathrm{p}}$ during tension to even higher values of the effective stresses $\mathrm{H}_{\mathrm{p}}$, while the values of $\mathrm{H}_{\mathrm{p}}$ during unloading remain constant almost until complete unloading, while maintaining the staged change in $\mathrm{H}_{\mathrm{p}}(\sigma)$ behind elastic limit.

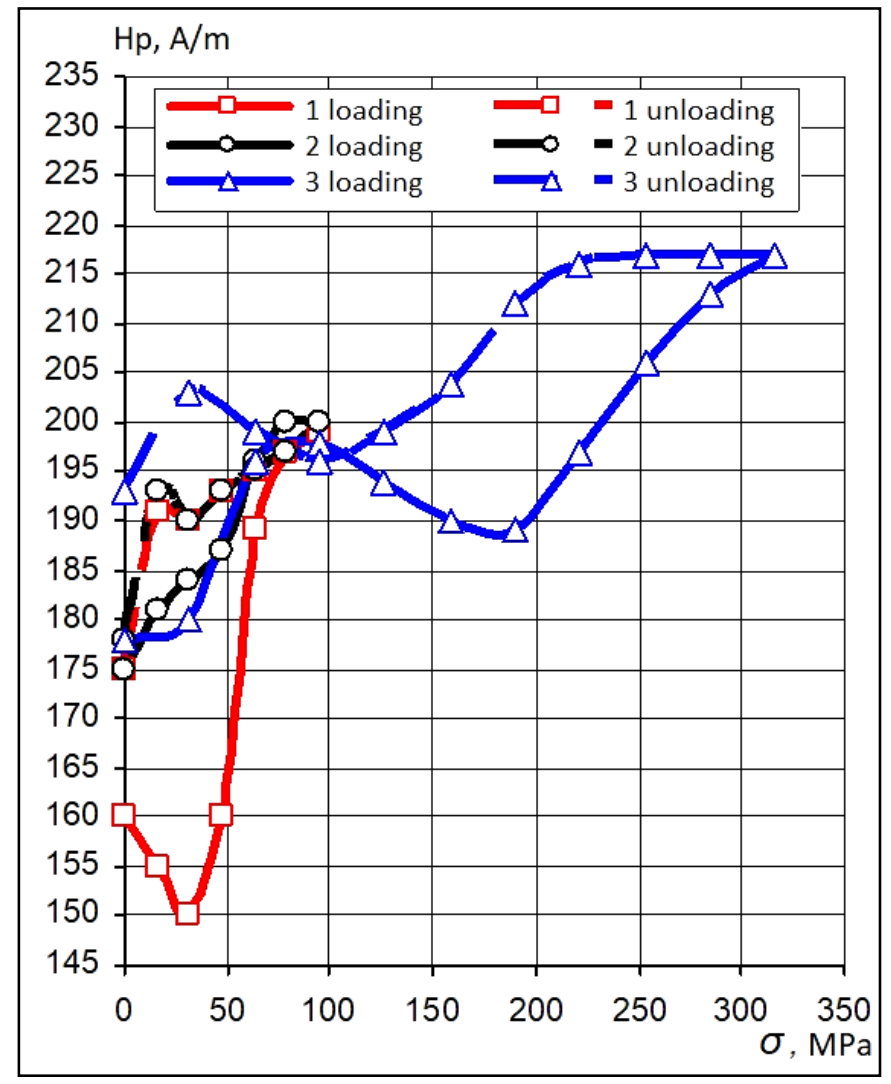

Fig. 7. Dependence of the magnetic field $\mathrm{H}_{\mathrm{p}}$ on tensile stresses for samples of 08ps steel in state (rolling at $\mathcal{E}=50 \%+$ recrystallization annealing).

A similar dependence $\mathrm{H}_{\mathrm{p}}(\sigma)$ is also observed for steels that have undergone preliminary cold plastic deformation at $\varepsilon=50 \%$ (Figs. 8, 9). It is seen that in this case a three-stage dependence of the growth of $\mathrm{H}_{\mathrm{p}}$ values on the acting stresses $\mathrm{s}$ is observed, and the minimum of $\mathrm{H}_{\mathrm{p}}$ is shifted to the region of higher acting stresses; during unloading, constant $\mathrm{H}_{\mathrm{p}}$ values are maintained. 


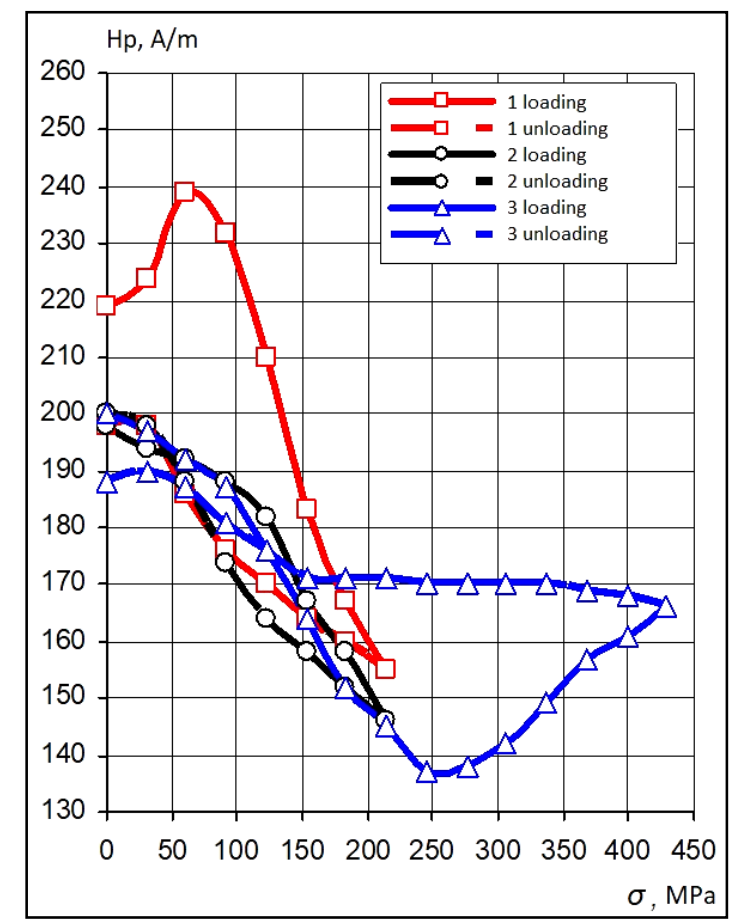

Fig. 8. Dependence of magnetic field strength $\mathrm{H}_{\mathrm{p}}$ on uniaxial tensile stresses for samples from $08 \mathrm{ps}$ steel in state (as-received condition + rolling at $E=50 \%$ ).

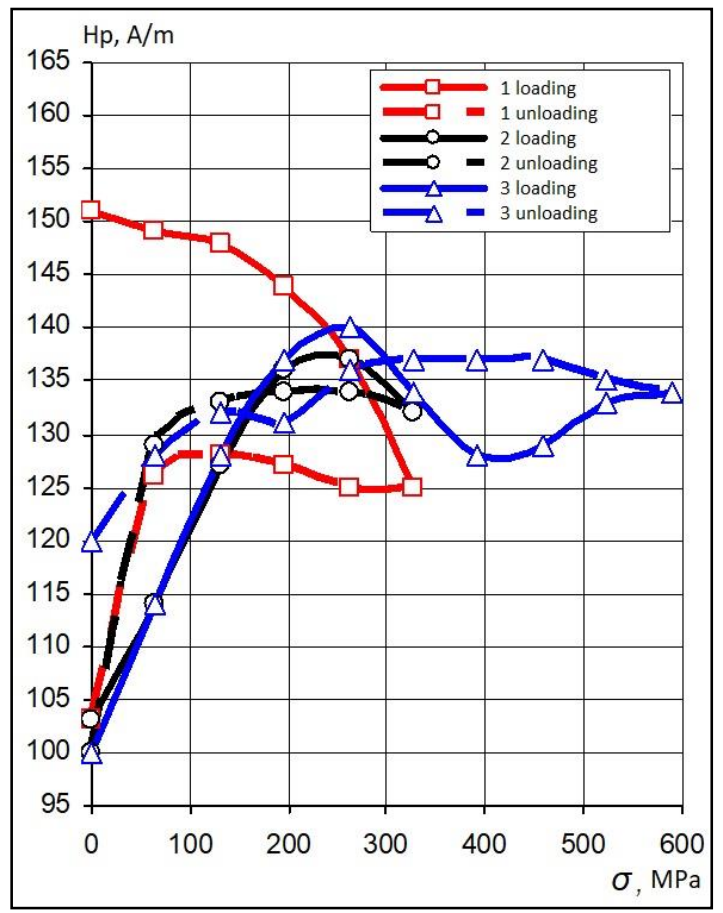

Fig. 9. Dependence of the magnetic field $\mathrm{H}_{\mathrm{p}}$ on uniaxial tensile stresses for samples from $09 \mathrm{Mn} 2 \mathrm{Si}$ steel in a state (as-received condition + rolling at $\varepsilon=50 \%$ ). 
It can be seen from the above that, with a decrease in the grain size for all the studied steels under uniaxial tension, the minimum $\mathrm{H}_{\mathrm{p}}$ values shift to the region of higher acting stresses, which increase in the presence of a fine-grained structure. During unloading, magnetic hysteresis with decreasing grain size takes on ever greater values, and in the presence of the initial fine-grained structure, as well as after cold plastic deformation, the values of $\mathrm{H}_{\mathrm{p}}$ during unloading remain almost constant.

It should be noted that the change in the shape of the magnetic hysteresis loop significantly depends on the type of previous treatment: for samples that have been annealed at $1050{ }^{\circ} \mathrm{C}$, a decrease in $\mathrm{H}_{\mathrm{p}}$ values begins immediately after unloading, while in samples with a fine-grained structure or after cold plastic deformation, $\mathrm{H}_{\mathrm{p}}$ values remain at the same level. A similar dependence of the change in the magnetic hysteresis loop during magnetization of a ferromagnet in strong magnetic fields is observed after annealing and after hardening, which indicates the identity of the processes of magnetization of ferromagnetic materials both in strong magnetic fields and in a weak magnetic field of the Earth, but with a change in the acting stresses.

Thus, the established relationship between the magnetic field strength $\mathrm{H}_{\mathrm{p}}$ and the acting stresses $s$ during the deformation of structural steels shows that during elastic deformation by tension with an increase in $\mathrm{s}$ above a certain value, $\mathrm{H}_{\mathrm{p}}$ values decrease, while in the plastic region they increase. In this case, the minimum of $\mathrm{H}_{\mathrm{p}}$ values with a decrease in the grain size shifts toward higher acting stresses.

With a decrease in stresses (unloading), a change in the magnetic parameter $H_{p}$ is delayed, as a result of which a magnetic hysteresis loop is formed. At the same time, with a decrease in the initial grain size of steel, there is an ever greater delay in the $\mathrm{H}_{\mathrm{p}}$ values, and for the very fine-grained structure obtained after thermal cycling (the finest-grained structure) and recrystallization annealing, this delay is observed almost until the samples are completely unloaded. A similar picture is observed during unloading of samples that underwent preliminary cold plastic deformation, which indicates the irreversible magnetization of samples in a weak magnetic field of the Earth.

The mathematical processing of experimental research data to identify the relationship between the scattering magnetic field strength and the stresses acting in the control zone on steel grades 08ps and 09Mn2Si made it possible to present the obtained direct and inverse dependencies in graphical and analytical form. Coefficients $a, b, c$ with quadratic dependencies can be presented in the form:

$$
\sigma=\mathrm{a} \cdot H_{p}^{2}+b \cdot H_{p}+c
$$

For a number of structural states of steels (Table 1), they are applicable at the stage of technical diagnostics when assessing the elastic stress-strain state of metal structures from steels that have corresponding residual magnetization levels of the metal in the control zones (Rayleigh region) and are close to those studied in chemical composition and properties.

Table 1. Structural states of steels.

\begin{tabular}{|c|c|c|c|c|}
\hline Material grade & \multicolumn{2}{|c|}{ 08ps } & \multicolumn{2}{c|}{ 09Mn2Si } \\
\hline $\begin{array}{r}\text { Structural } \\
\text { State }\end{array}$ & $\begin{array}{c}\text { As-received } \\
\text { condition }\end{array}$ & $\begin{array}{c}\text { Annealing } \\
\text { at 900 }{ }^{\circ} \mathbf{C}\end{array}$ & $\begin{array}{c}\text { As-received } \\
\text { condition }\end{array}$ & $\begin{array}{c}\text { Annealing } \\
\text { at 1050 }{ }^{\circ} \mathbf{C}\end{array}$ \\
\hline Equation coefficients & -0.0191 & 0.0759 & -0.0036 & -0.0588 \\
\hline a & 3.4978 & -32.854 & -0.2987 & 19.886 \\
\hline $\mathrm{b}$ & 46.155 & 3545.2 & 222.99 & -1520.5 \\
\hline
\end{tabular}


The use of the obtained partial graphical and analytical quadratic dependences allows one to significantly simplify the methodology and intensify the process of practical determination of the acting stresses in stress concentration zones at one or another load level of the metal structures of operated hoisting cranes.

Regularities in the variation of the scattering magnetic field strength from the acting stresses $\mathrm{H}_{\mathrm{p}}(\sigma)$ obtained on low-carbon and low-alloy steels under cyclic elastic-plastic deformation (during loading and unloading) can be extended to other structural steels similar to those studied by chemical composition and strength classes, and can be used in assessing the stress-strain state of the metal structures of operated hoisting cranes.

Based on experimental studies [3-7] conducted on laboratory samples of low-carbon (08ps) and low-alloy (09Mn2Si) steels with different initial microstructures, a methodology was developed for assessing the technical condition of welded load-bearing metal structures of operated hoisting cranes, the algorithm of which is shown in Fig. 10.

A distinctive feature of the technique is the use, along with various methods of destructive and non-destructive testing, of a passive flux-gate method, which allows one to identify stress concentration zones in welded joints and structural elements of hoisting machines, to assess their degree of danger and indirectly determine the actual values of acting stresses in these zones, which are recommended to use in further strength calculations.

In addition, the passive flux-gate method allows to carry out both continuous and selective control of welded joints and elements of metal structures, including inspection of hard-to-reach spots, as well as closed circuits, taking into account the unknown mechanical and magnetic background of the metal without preliminary removing the non-magnetic protective coating with a thickness of less than $3 \mathrm{~mm}$.

Regardless of the loading conditions of the metal structures of hoisting cranes (under load, after its removal), if necessary, a continuous magnetic scan of the surface of metal structures without preliminary preparation, including units, elements and welded joints, is carried out. On welded joints, first of all, scanning of the fusion zone of the weld with the base metal (as the most dangerous) is carried out; secondly, the weld zone is scanned. When scanning, places of significant changes in the intensity of the scattering magnetic field $\mathrm{H}_{\mathrm{p}}$ are noted, having extreme values of any sign. These assumed zones of stress concentration can be characterized by both maximum and minimum values of $\mathrm{H}_{p}$ with the sign "+" or "-", as well as $\mathrm{H}_{\mathrm{p}}$ values that differ from the bulk of the values in structural elements. In the case of presence of local defects (mechanical, corrosion damage, slag inclusions), significant local deviations of $\mathrm{H}_{\mathrm{p}}$ values are possible.

After finding the zones of stress concentration in the elements and units of the structures, three options for further research are possible:

- if the object was previously subjected to magnetic control, then the measured values of the magnetic parameter $\mathrm{H}_{\mathrm{p}}$ are compared with previously obtained ones, on the basis of which a decision is made on whether to continue further research, or to stop them if there are no changes in $\mathrm{H}_{\mathrm{p}}$;

- with significant deviations of the $\mathrm{H}_{\mathrm{p}}$ values in some zones of the $\mathrm{SC}$, they can be followed up by other non-destructive testing methods (ultrasonic testing, X-ray, etc.) in order to identify unacceptable defects. The use of such a combined control significantly reduces the complexity of control;

- the actual estimate of the metal stress-strain state in stress concentration zones. For this, it is necessary to conduct a preliminary metallographic analysis of the structure and, if possible, mechanical testing of samples cut from the elements of the metal structures under study or from similar steel, in order to adjust the dependence of the change in the magnetic parameter $\mathrm{H}_{\mathrm{p}}$ on the acting stresses during loading, taking into account the actual microstructure of the metal structures of hoisting cranes. 


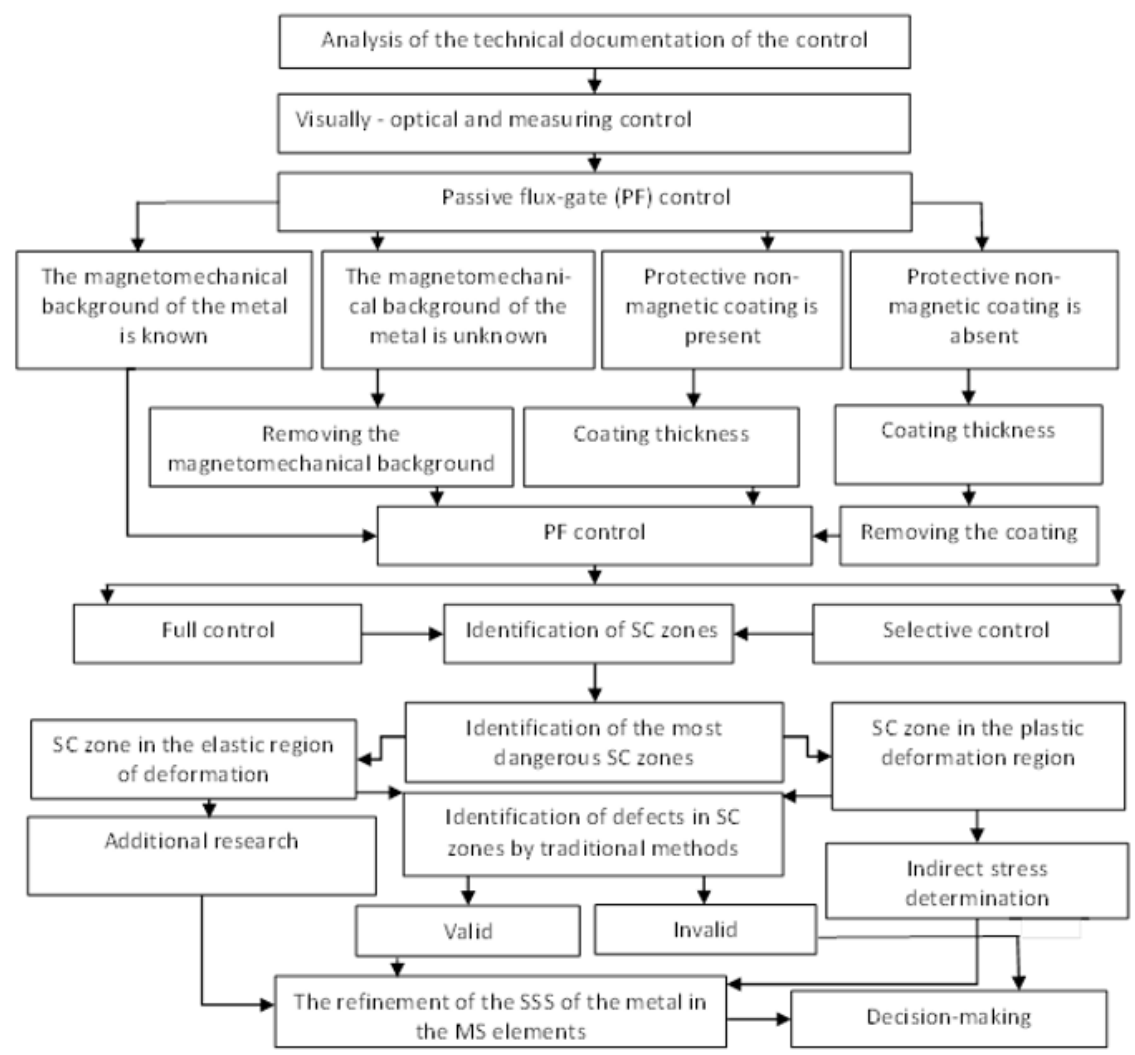

Fig. 10. Algorithm for assessing the stress-strain state of welded load-bearing metal structures of operated hoisting cranes.

Then, taking into account the obtained experimental data, an assessment is made of the correspondence of the identified SC zones to elastic or plastic deformation regions. For this, depending on the type of loading of the structure, two-, three- or more-fold stepwise unloading-loading or loading-unloading of the structure, as a result of which a change in the parameter $\mathrm{H}_{\mathrm{p}}$ depending on the change in the acting stresses (or from the load $P$ ) is carried out.

When processing experimental data, $\mathrm{H}_{\mathrm{p}}$ values are estimated to determine the sign of the acting stresses (tension - compression); the magnitude of the change in $\mathrm{H}_{\mathrm{p}}$ after each stepwise change in the applied load both during loading and during unloading (in order to assess the degree of danger of the identified zones of SC); proportionality of the change in the $\mathrm{H}_{\mathrm{p}}$ values to the applied stepwise loads (acting stresses) to determine the fulfillment of Hooke's law are evaluated. In the case of its implementation, the acting stresses will always be below the limit of proportionality. If a slight violation of proportionality is noticeable, then the acting voltages practically correspond to the limit of proportionality. With larger deviations, the magnitude of the acting stresses will exceed the proportionality limit, but will be lower than the yield stress. A decrease in the increment $\mathrm{H}_{\mathrm{p}}$ from the applied load indicates the approximation of the acting stresses to the stresses of the yield strength.

By the nature of the change in $\mathrm{H}_{\mathrm{p}}(\sigma)$ during the stepwise cyclic loading of the structure, the following problems are solved:

- sign of stresses acting in the zone of SC (tension or compression) is determined; 
- area of deformation (elastic, plastic) of each zone of the SC is determined.

The degree of danger of the identified zones of SC, as well as the level of acting stresses is estimated by changes in $\mathrm{H}_{\mathrm{p}}(\sigma)$. When assessing the degree of danger of the SC zones, the increment $\mathrm{H}_{\mathrm{p}}$ obtained by stepwise loading - unloading of the structure (structural elements) is taken into account: the higher the increment, the greater the acting stresses and the greater the degree of danger of the identified SC zones. In the most dangerous zones of the SC, the level of acting stresses is determined by the nature of the change in $\mathrm{H}_{\mathrm{p}}(\sigma)$ :

- acting stresses correspond to the proportionality limit for a given steel grade (due to violation of the proportionality of the change in the values of $\mathrm{H}_{\mathrm{p}}(\sigma)$ )

- acting stresses below the limit of proportionality (there is no violation of the proportionality of the change in $\mathrm{H}_{\mathrm{p}}(\sigma)$ );

- acting stresses above the proportionality limit (a deviation of the proportional change in $\mathrm{H}_{\mathrm{p}}(\sigma)$ is observed);

- acting stresses correspond to the yield strength (there are practically no changes in $\mathrm{H}_{\mathrm{p}}$ when the external load changes);

- acting stresses below yield strength;

- acting stresses above yield strength.

In the latter case, the degree of exceeding the yield strength by the acting stresses is estimated from the change in the closing curve of the magnetic hysteresis loop: the more it delays, the higher the degree of plastic deformation in a given stress concentration zone.

The magnitude of the acting stresses can be simultaneously estimated using strength calculations. In the process of comparing the obtained results, an assessment of the stressstrain state of the elements of the studied structures is carried out. It should be noted that the calculated values of the acting stresses can have slightly lower values than those obtained from the results of magnetic measurements. This is largely due to the fact that during the calculation it is impossible to take into account all factors affecting the magnitude of the acting stresses (presence of defects, dispersion of mechanical properties, structural changes in structural elements, load redistribution during operation, simplification of the design scheme), whereas when magnetic measurements are controlled by the actual values of the acting voltages.

\section{Conclusion}

Thus, the result of the study was the development of a method for determining the acting stresses in the metal structures of hoisting cranes, which, by the nature and magnitude of the change in the residual magnetization of the scattering field during their stepwise loading (unloading), allows us to judge about the magnitude of the acting stresses. A patent of the Russian Federation for an invention was obtained for the developed method. The study developed a methodology for assessing the technical condition of welded load-bearing metal structures of hoisting cranes based on the integrated use of passive flux-gate and other control methods, which allows determining the active stresses used in strength calculations in the identified hazardous zones of concentration of stresses of metal structures.

The application of the developed methodology for assessing the technical condition of welded load-bearing metal structures made it possible to increase the efficiency and productivity of technical diagnostics by $20 \%$, draw reasonable conclusions and give recommendations for further reliable and safe operation. 


\section{References}

1. V.G. Kuleev, Defektoskopiya 11, 3-18 (1997)

2. V.F. Muzhickij, B.E. Popov, G.Y. Bezlyudko, Diagnostika 3, 15-19 (2002)

3. V.E. Gordienko, N.V. Ovchinnikov, A.O. Baksheev, Diagnostika 2, 60-64 69 (2007)

4. V.E. Gordienko, N.V. Ovchinnikov, A.O. Baksheev, Zhilishchnoe stroitel'stvo1, 11-12 (2007)

5. A. Scherbakov, D. Monastyreva, V. Smirnov, E3S Web of Conferences 135, 03022 (2019) https://doi.org/10.1051/e3sconf/201913503022

6. V.E. Gordienko, I.A. Ivanov, A.A. Abrosimova, A.P. Scherbakov, Bulletin of Civil Engineers 4(69), 150-155 (2018) DOI: 10.23968 / 1999-5571-2018-15-4-150-155

7. V.E: Gordienko, A.A. Abrosimova, O.V. Kuzmin, E.V. Trunova, Bulletin of civil Engineers 1(66), 128-133 (2018) DOI: 10.23968 / 1999-5571-2018-15-1-128-133 